\title{
Investigação da dependência psicológica da prática da canoagem em atletas da seleção brasileira
}

\author{
Luiz Fernando Cuozzo Lemos ${ }^{1}$ \\ Clarissa Stefani Teixeira ${ }^{2}$ \\ Luis Felipe Dias Lopes ${ }^{3}$
}

\begin{abstract}
${ }^{1}$ Mestrando em Educação Física e Esportes pela Universidade de Brasília, DF, Brasil
${ }^{2}$ Doutoranda em Engenharia da Produção pela Universidade Federal de Santa Catarina, Florianópolis, SC, Brasil

${ }^{3}$ Engenharia da Produção pela Universidade Federal de Santa Catarina, Florianópolis, SC, Brasil e Departamento de estatística da Universidade Federal de Santa Maria, RS, Brasil
\end{abstract}

\begin{abstract}
Resumo: A canoagem como modalidade competitiva, exige técnicas especificas de treinamento utilizando os mais variados métodos de sistematização do treinamento competitivo. Com o crescimento do esporte a dependência dos atletas para com suas modalidades é um dos fatores preocupantes. Logo, procurou-se identificar os aspectos da dependência da modalidade nos atletas da seleção brasileira de canoagem velocidade. Para isso, foi adaptado o questionário de Rosa, Mello e Souza-Formigoni (2003), que busca relações com os aspectos psicológicos relacionados às atividades desenvolvidas pelos atletas. Foram avaliados 19 atletas da seleção brasileira de canoagem velocidade (12 do sexo masculino e 7 do sexo feminino). Os resultados mostraram que em algumas questões ambos os sexos apresentam-se dependentes do esporte - fato que é o elemento fundamental para as escolhas que irão compor o estilo de vida. No entanto, não foram encontradas diferenças estatisticamente significativas entre os sexos para a dependência do esporte.
\end{abstract}

Palavras-chave: Esporte. Canoagem. Dependência da atividade física. Aspectos psicológicos.

The investigation of the psychological dependence on canoeing practice in athletes from the brazilian team

\begin{abstract}
Canoeing, in a competitive mode, requires specific technical training using the most varied methods of systematic competitive training. Because of the evolution of this sport, the dependency of athletes to its modalities is one of the concern factors. Therefore, we tried to recognize the aspects of the dependency of the athletes in the Brazilian selection of canoe flatwater. To this, was used the questionnaire that was adapted from Rosa, Mello and Souza Formigoni (2003), which seeks relations with the psychological aspects related to the athletes' activities. 19 athletes were from the national canoeing team (12 male and 7 female gender) were assessed. The results showed that in some issues the two genders have been dependent on the sport -a fact that is the key to the choices that will compose the lifestyle. However, there were no statistically significant differences between genders to the dependence of the sport.
\end{abstract}

Key Words: Sport. Canoeing. Dependence on physical activity. Psychological aspects.

\section{Introdução}

A canoagem, modalidade antiga e popular, teve seu início com os esquimós, povo que necessitava de embarcações rápidas e ágeis para seu deslocamento e pesca (LEMOS, PRANKE e TEIXEIRA, 2007). No Brasil, a canoagem competitiva é muito recente. A Confederação Brasileira de Canoagem (CBCa) tem apenas vinte anos de existência, porém este pequeno tempo não foi empecilho para que os atletas obtivessem bons resultados (LEMOS, PRANKE e TEIXEIRA, 2007). Por outro lado, a pequena existência de trabalhos e publicações científicas relacionadas à canoagem afeta o bom desenvolvimento do esporte. Logo, pesquisas são essenciais para a preparação do trabalho de treinamento físico e intelectual dos canoístas.

Como a canoagem é um esporte de alto rendimento, esta necessita de intensos treinamentos, em torno de 6 a 8 horas diárias (BORGES, 2008). Porém, muitos autores indicam que a prática excessiva de exercícios está associada a aspectos prejudiciais a saúde dos indivíduos (BAMBER, COCKERILL e CARROLL, 2000; BAMBER et al., 2000; MORGAN, 1979). Isto se torna relevante, pois a prática excessiva de exercícios poderia desencadear um 
comportamento compulsivo (ROSA, MELLO e SOUZA-FORMIGONI, 2003). Muitas vezes, isso é claramente observado em atletas, principalmente naqueles que continuam a prática das modalidades mesmo quando se encontram doentes, lesionados ou com qualquer contra indicação médica (DECOVERLEY, 1987).

Nesse sentido, existem alguns instrumentos desenvolvidos para o estudo da dependência de exercícios e suas relações com os aspectos psicológicos. Rosa, Mello e Souza-Formigoni (2003) com objetivo de testar uma amostra de maratonistas brasileiros, traduziram a adaptação da Escala de Dependência de Corrida proposta por Hailey e Bailey (1982). Porém, estudos relacionados com a modalidade de canoagem não foram encontrados no que tange as questões de dependência da modalidade.

Diante disso, este estudo buscou investigar a dependência do esporte em atletas da seleção brasileira de canoagem velocidade do sexo masculino e feminino. Este estudo poderá auxiliar e fornecer recursos aos treinadores e psicólogos com informações relevantes quanto ao tempo, carga horária e, principalmente, a dependência da canoagem em seus atletas que se relaciona as questões da escala de dependência psicológica.

\section{Material e Métodos}

A Seleção Brasileira de canoagem, no momento da coleta de dados, contava com 20 atletas, sendo 13 do sexo masculino e sete do sexo feminino. Todos foram convidados a participar do estudo e aqueles que concordaram em participar da coleta, assinaram um Termo de Consentimento Livre e Esclarecido conforme resolução 196/1996 do Conselho Nacional da Saúde, do Ministério da Saúde. Todos os indivíduos, que concordaram em participar do estudo, preencheram o questionário fornecido pelos pesquisadores individualmente, sendo garantido total sigilo da confidencialidade dos indivíduos. Nesse sentido, apenas um atleta do sexo masculino se recusou em participar do estudo.

Foram avaliados 19 atletas, sendo 12 atletas do sexo masculino com idades de 20,58 $\pm 4,06$ anos (máximo de 31 anos e mínimo de 18 anos) e 7 atletas do sexo feminino, com idades de $18,71 \pm 3,15$ anos (máximo de 25 anos e mínimo de 14 anos). O tempo de prática do grupo de estudo foi de 6,11 $\pm 3,38$ anos (mínimo de 3 anos e máximo de 18 anos) em canoagem.

\section{Escala de dependência da canoagem}

Uma adaptação do questionário de dependência da prática de corrida de Rosa, Mello e Souza-Formigoni (2003) foi realizada, ilustrado no Quadro 1. Assim como o instrumento original, - presente questionário avalia os aspectos psicológicos da dependência de exercício, neste representado pela canoagem, por meio de uma escala de 14 itens, atribuindo-se a cada item um escore (0 ou 1 ).

De acordo com as respostas da escala de dependência foram aplicadas as seguintes pontuações: um (1) ponto para toda resposta "concordo muito" nas questões de 4 até 9 e nas questões de 11 até 12 . Um (1) ponto para a resposta "discordo muito" na questão 10 . Um (1) ponto se as questões $1=a$; $2=a$ ou $b$ e $3=b$. Para cada resposta afirmativa nos itens $\mathrm{B}$ e/ou $\mathrm{H}$ na questão 13 atribuiu-se um (1) ponto. Diante dessa classificação foi efetuada a soma de todo o questionário, representando a pontuação total obtida pelos atletas, com no mínimo zero pontos (menor dependência) e no máximo 14 pontos (maior dependência), conforme pontuação determinada acima). Os escores mais altos estão relacionados a maiores níveis da dependência de canoagem. Além da escala foram acrescentadas questões relacionadas à idade, sexo e tempo de prática dos indivíduos.

Para análise dos dados primeiramente foi utilizada estatística descritiva, por meio da média, desvio padrão, valores máximos, mínimos e percentual das respostas. Em um segundo momento foi utilizado o teste de correlação de Spearman para as associações entre a pontuação total da escala de dependência e cada questão do questionário. Para verificação da homogeneidade dos percentuais de cada questão e do total da escala de dependência entre os sexos foi utilizado o teste Qui-Quadrado e Teste Exato de Fisher. O nível de significância utilizado para todos os testes foi de $5 \%$.

O critério adotado por Malina (1996) foi utilizado para descrição das correlações em: correlação baixa para valores menores que 0,30 , moderada para valores entre 0,30 e 0,60 e alta para valores superiores a 0,60 . 
Quadro 1. Questionário de dependência da canoagem

\begin{tabular}{|c|c|c|c|}
\hline \multicolumn{4}{|c|}{ QUESTIONÁRIO DE DEPENDÊNCIA DA PRÁTICA DE EXERCÍCIOS (Canoagem) } \\
\hline \multicolumn{2}{|r|}{ Nome: } & Idade: & Tempo de prática: \\
\hline 1. & $\begin{array}{l}\text { Durante u } \\
\text { a) } \\
\text { b) } \\
\text { c) } \\
\text { d) } \\
\text { e) }\end{array}$ & $\begin{array}{l}\text { ma semana normal eu remo: } \\
\text { todos os dias } \\
6 \text { dias } \\
5 \text { dias } \\
4 \text { dias } \\
\text { é invariável }\end{array}$ & $\begin{array}{l}\text { 2. Nos dias em que eu não treino, normalmente me } \\
\text { sinto: } \\
\text { a) tenso } \\
\text { b) culpado } \\
\text { c) igual aos outros dias nos quais remo } \\
\text { d) outros (especificar) } \\
\end{array}$ \\
\hline 3. & \multicolumn{2}{|c|}{$\begin{array}{l}\text { Desde que comecei a treinar canoagem, meu } \\
\text { interesse em divertir-me em outras atividades } \\
\text { sociais tem: } \\
\text { a) aumentado } \\
\text { b) diminuído } \\
\text { c) mantendo-se o mesmo }\end{array}$} & $\begin{array}{l}\text { 4. No dia em que não treino canoagem, sinto-me } \\
\text { deprimido ou mentalmente devagar: } \\
\text { (1) concordo muito } \\
\text { (2) concordo moderadamente } \\
\text { (3) concordo pouco } \\
\text { (4) discordo pouco } \\
\text { (5) discordo muito }\end{array}$ \\
\hline 5. & \multicolumn{2}{|c|}{$\begin{array}{l}\text { No dia em que eu não treino canoagem, sinto que } \\
\text { me falta algo: } \\
\text { (1) concordo muito } \\
\text { (2) concordo moderadamente } \\
\text { (3) concordo pouco } \\
\text { (4) discordo pouco } \\
\text { (5) discordo muito }\end{array}$} & $\begin{array}{l}\text { 6. Se parasse de treino canoagem minha saúde } \\
\text { física declinaria significativamente. } \\
\text { (1) concordo muito } \\
\text { (2) concordo moderadamente } \\
\text { (3) concordo pouco } \\
\text { (4) discordo pouco } \\
\text { (5) discordo muito }\end{array}$ \\
\hline & \multicolumn{2}{|c|}{$\begin{array}{l}\text { Experimento um alto nível de prazer na maioria } \\
\text { das minhas sessões treino. } \\
\text { (1) concordo muito } \\
\text { (2) concordo moderadamente } \\
(3) \text { concordo pouco } \\
(4) \text { discordo pouco } \\
\text { (5) discordo muito } \\
\end{array}$} & $\begin{array}{l}\text { 8. Treinar canoagem é minha principal forma de } \\
\text { recreação. } \\
\text { (1) concordo muito } \\
\text { (2) concordo moderadamente } \\
\text { (3) concordo pouco } \\
\text { (4) discordo pouco } \\
\text { (5) discordo muito }\end{array}$ \\
\hline & \multicolumn{2}{|c|}{$\begin{array}{l}\text { Canoagem é um assunto comum em minhas } \\
\text { conversas. } \\
\text { (1) concordo muito } \\
\text { (2) concordo moderadamente } \\
\text { (3) concordo pouco } \\
\text { (4) discordo pouco } \\
\text { (5) discordo muito }\end{array}$} & $\begin{array}{l}\text { 10. É importante para todos aqueles que treinam } \\
\text { canoagem, interrompam por algum tempo suas } \\
\text { rotinas de treinamento. } \\
\text { (1) concordo muito } \\
\text { (2) concordo moderadamente } \\
(3) \text { concordo pouco } \\
\text { (4) discordo pouco } \\
\text { (5) discordo muito }\end{array}$ \\
\hline 11. & $\begin{array}{l}\text { o de } v \\
\text { (1) } \\
(2) \\
(3) \\
(4) \\
(5)\end{array}$ & $\begin{array}{l}\text { canoagem têm influenciado meu } \\
\text { icordo muito } \\
\text { רcordo moderadamente } \\
\text { רcordo pouco } \\
\text { cordo pouco } \\
\text { cordo muito }\end{array}$ & $\begin{array}{l}\text { 12. Meu interesse pela canoagem tem causado } \\
\text { alguns problemas nas minhas relações familiares } \\
\text { e interpessoais. } \\
\text { (1) concordo muito } \\
\text { (2) concordo moderadamente } \\
(3) \text { concordo pouco } \\
(4) \text { discordo pouco } \\
\text { (5) discordo muito }\end{array}$ \\
\hline 13. & $\begin{array}{c}\text { Marque a } \\
\text { A) } \\
\text { B) } \\
\text { C) }\end{array}$ & \multicolumn{2}{|c|}{$\begin{array}{l}\text { Tenho um companheiro de treinos com o qual eu pratico minhas sessões sempre que possível. } \\
\text { Eu mantenho um registro por escrito de minhas sessões treinamento. } \\
\text { Eu planejo minhas outras atividades baseado no tempo que eu quero treinar canoagem. } \\
\text { Sou normalmente disciplinado e treino mesmo nos dias que realmente não estou disposto para treinar. } \\
\text { Eu estabeleço metas para minhas sessões de treino na semana. } \\
\text { Eu sou capaz de alcançar as metas das minhas sessões de treinamento que planejei para a semana. } \\
\text { Sinto que se não mantiver minha auto disciplina, pararia completamente de treinar no dia seguinte. }\end{array}$} \\
\hline
\end{tabular}

\section{Resultados}

De acordo com o resultado da primeira questão do questionário, $100 \%$ das atletas femininas treinavam 6 dias na semana e da mesma forma essas treinavam a mais de 3 anos $(4,71 \pm 2,06$ anos $)$ a aproximadamente no mesmo horário todos os dias de treinamento, mesmo quando indisposição à pratica do treino. Já os atletas do sexo masculino $25 \%$ treinavam 7 dias na semana e $75 \%$ treinavam 6 dias na semana. Estes atletas afirmaram ter um tempo de prática da modalidade de 3 a 18 anos, sendo que a média da prática desta modalidade foi $6,92 \pm 3,80$ anos. Assim como nas atletas do sexo feminino, todos os homens também treinavam no mesmo horário e todos os dias, mesmo quando possuem indisposição à prática do treino. 
De acordo com a segunda pergunta do questionário, a Tabela 1 ilustra o percentual de atletas de ambos os sexos que se sente culpado, tenso ou igual por um dia de treinamento que não é realizado. Nesta questão, não foram encontradas diferenças estatisticamente significativas entre os sexos.

Tabela 1. Percentual de atletas de ambos os sexos que se sente culpado, tenso ou igual por um dia de treinamento que não é realizado.

\begin{tabular}{ccc}
\hline $\begin{array}{c}\text { Respostas da segunda } \\
\text { questão }\end{array}$ & \multicolumn{2}{c}{ Sexo } \\
\cline { 2 - 3 } & Masculino & Feminino \\
\hline Culpado (a) & $16,67 \%$ & $28,57 \%$ \\
Tenso (a) & $16,67 \%$ & $0,00 \%$ \\
Igual & $25,00 \%$ & $0,00 \%$ \\
Outro (relaxado (a), & $41,67 \%$ & $71,43 \%$ \\
\hline normal, mais cansado (a) & & \\
\hline
\end{tabular}

A percepção das atividades sociais realizadas pelos atletas do sexo masculino e feminino durante o período de treinamento foi verificada por meio da terceira pergunta do questionário e a Tabela 2 ilustra as respostas. As comparações entre os sexos indicaram diferenças estatisticamente significativas com nível de significância de 0,031 .

Tabela 2. Percepção em relação a outras atividades sociais.

\begin{tabular}{ccc}
\hline Percepção em & \multicolumn{2}{c}{ Sexo } \\
\cline { 2 - 3 } relação a outras & Masculino & Feminino \\
atividades sociais & & $0,00 \%$ \\
\hline Aumentado & $41,67 \%$ & $85,71 \%$ \\
Diminuído & $25,00 \%$ & $14,29 \%$ \\
Manteve-se o & $33,33 \%$ & \\
mesmo & 3,30 & \\
\hline
\end{tabular}

A Tabela 3 ilustra as respostas dos atletas do sexo masculino ( $(\hat{)})$ e sexo feminino (ㅇ) relacionando o sentimento, lazer, saúde e seus estilos de vida com a prática do esporte. Os números de "4" a " 12 " representam as afirmações relacionadas às questões do questionário do Quadro 1.

Tabela 3. Respostas dos atletas relacionadas ao efeito do esporte canoagem no sentimento, lazer, saúde e seus estilos de vida.

\begin{tabular}{|c|c|c|c|c|c|c|c|c|c|c|}
\hline & \multicolumn{2}{|c|}{$\begin{array}{l}\text { Concordo } \\
\text { Muito }\end{array}$} & \multicolumn{2}{|c|}{$\begin{array}{c}\text { Concordo } \\
\text { moderadamente }\end{array}$} & \multicolumn{2}{|c|}{$\begin{array}{l}\text { Concordo } \\
\text { pouco }\end{array}$} & \multicolumn{2}{|c|}{$\begin{array}{l}\text { Discordo } \\
\text { muito }\end{array}$} & \multicolumn{2}{|c|}{$\begin{array}{l}\text { Discordo } \\
\text { pouco }\end{array}$} \\
\hline & 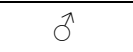 & q & $\hat{\sigma}$ & o & 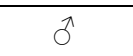 & 우 & o & क & $\pi$ & o \\
\hline 4 & $0,00 \%$ & $0,00 \%$ & $8,33 \%$ & $0,00 \%$ & $41,67 \%$ & $71,43 \%$ & $16,67 \%$ & $28,57 \%$ & $33,33 \%$ & $0,00 \%$ \\
\hline 5 & $41,67 \%$ & $28,57 \%$ & $0,00 \%$ & $0,00 \%$ & $41,67 \%$ & $45,86 \%$ & $0,00 \%$ & $28,57 \%$ & $16,67 \%$ & $0,00 \%$ \\
\hline 6 & $33,33 \%$ & $14,29 \%$ & $16,67 \%$ & $14,29 \%$ & $33,33 \%$ & $28,57 \%$ & $0,00 \%$ & $14,29 \%$ & $8,33 \%$ & $28,57 \%$ \\
\hline 7 & $58,33 \%$ & $42,86 \%$ & $16,67 \%$ & $57,14 \%$ & $16,67 \%$ & $0,00 \%$ & $0,00 \%$ & $0,00 \%$ & $0,00 \%$ & $0,00 \%$ \\
\hline 8 & $41,67 \%$ & $14,29 \%$ & $0,00 \%$ & $57,14 \%$ & $33,33 \%$ & $28,57 \%$ & $8,33 \%$ & $0,00 \%$ & $8,33 \%$ & $0,00 \%$ \\
\hline 9 & $66,67 \%$ & $42,86 \%$ & $16,67 \%$ & $42,86 \%$ & $16,67 \%$ & $28,57 \%$ & $0,00 \%$ & $0,00 \%$ & $0,00 \%$ & $0,00 \%$ \\
\hline 10 & $33,33 \%$ & $57,14 \%$ & $8,33 \%$ & $42,86 \%$ & $25,00 \%$ & $0,00 \%$ & $8,33 \%$ & $0,00 \%$ & $16,67 \%$ & $0,00 \%$ \\
\hline 11 & $75,00 \%$ & $71,42 \%$ & $0,00 \%$ & $14,29 \%$ & $25,00 \%$ & $14,29 \%$ & $0,00 \%$ & $0,00 \%$ & $0,00 \%$ & $0,00 \%$ \\
\hline 12 & $0,00 \%$ & $14,29 \%$ & $16,67 \%$ & $0,00 \%$ & $25,00 \%$ & $14,29 \%$ & $16,67 \%$ & $14,29 \%$ & $41,67 \%$ & $57,13 \%$ \\
\hline
\end{tabular}

As comparações entre os sexos para as questões de 4 à 12 mostraram diferenças estatisticamente significativas apenas para a questão 8, com nível de significância de 0,019.

Com relação à questão 13 , a percepção dos atletas do sexo feminino foi semelhante aos atletas do sexo masculino. Apenas a questão $13 \mathrm{~b}$ (eu treino em ambientes desfavoráveis) se mostrou com diferenças entre os sexos, $(p=0,007)$ sendo que nenhuma mulher afirmou treinar em dias desfavoráveis.

A Figura 1 ilustra as alternativas que se aplicam ao comportamento de treino dos atletas, os quais as letras correspondem os seguintes questionamentos: 


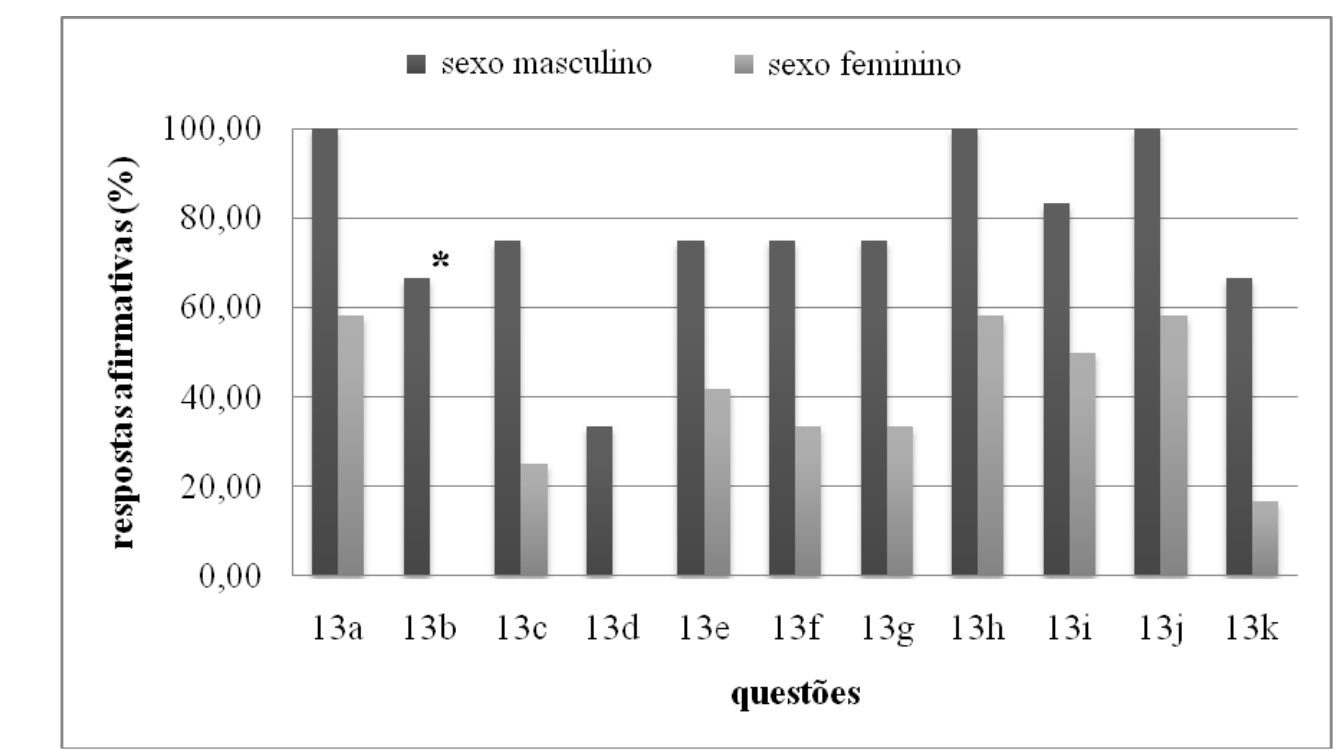

* Diferença estatisticamente significativa com nível de significância ( $p$ ) menor que 0,05.

Figura 1. Comportamento de treino dos atletas do sexo masculino e feminino da seleção brasileira de canoagem.

Com relação à investigação da dependência dos atletas do sexo masculino e feminino da seleção brasileira de canoagem, a Tabela 4 mostra os resultados obtidos por meio do cálculo dos escores do questionário. As comparações do percentual entre os sexos mostraram que os dados de dependência são estatisticamente iguais.

Tabela 4. Escores da dependência da prática de canoagem.

\begin{tabular}{rccc}
\hline Atletas & $\begin{array}{c}\text { Número } \\
\text { de } \\
\text { atletas }\end{array}$ & $\begin{array}{c}\text { Pontuação da } \\
\text { dependência } \\
\text { da canoagem }\end{array}$ & $p$ \\
\hline Masculino & 12 & 6,08 & 0,176 \\
Feminino & 7 & 4,43 & \\
\hline
\end{tabular}

Os valores da correlação de Spearman $(r)$ e o nível de significância $(p)$ das associações entre a escala total de dependência dos atletas e cada questão do questionário estão ilustrados na Tabela 5. Para o sexo masculino as questões 5, 8 e 9 se mostraram com correlações significativas. Estes resultados demonstram que quanto maior a pontuação total da escala de dependência maior é a tendência de se concordar muito com a questão analisada. Por exemplo, na questão 5 (no dia em que eu não treino canoagem, sinto que me falta algo) há uma tendência de os atletas do sexo masculino afirmarem que sim, ou seja, que concordam muito que nos dias em que os mesmos não treinam há sentimento que falta algo. Na questão 8 há uma tendência em se concordar muito que o treinamento da canoagem seja a principal forma de recreação e, na questão 9 , há uma tendência em se concordar muito que a canoagem seja o principal assunto das conversas dos atletas.

Da mesma forma, na questão 7 os resultados podem ser interpretados para o sexo feminino. Neste caso, há uma tendência em se concordar muito que durante a maioria das sessões de treinamento há um alto nível de prazer. De acordo com o critério proposto por Malina (1996) todas as correlações encontradas podem ser consideradas altas já que os valores são maiores que 0,60 .

Tabela 5. Associação entre a pontuação da dependência da canoagem e as questões do questionário para os sexos feminino e masculino.

\begin{tabular}{|c|c|c|c|}
\hline Sexo & Questão & Pon & $\begin{array}{l}\text { lependência da } \\
\text { ggem }\end{array}$ \\
\hline \multirow{6}{*}{ Masculino } & \multirow{2}{*}{5} & $\mathrm{R}$ & $-0,642$ \\
\hline & & $p^{*}$ & 0,024 \\
\hline & \multirow{2}{*}{8} & $\mathrm{R}$ & $-0,806$ \\
\hline & & $p^{*}$ & 0,002 \\
\hline & \multirow{2}{*}{9} & $\mathrm{R}$ & $-0,728$ \\
\hline & & $p^{*}$ & 0,007 \\
\hline \multirow{2}{*}{ Feminino } & \multirow{2}{*}{7} & $\mathrm{R}$ & $-0,874$ \\
\hline & & $p^{*}$ & 0,010 \\
\hline
\end{tabular}

* Valores menores que 0,05 indicam significância 
A Figura 2 ilustra um diagrama de dispersão, para cada sexo, da questão que apresentou associação mais forte (questão 8 para o sexo masculino e questão 7 para o sexo feminino) com a pontuação total.
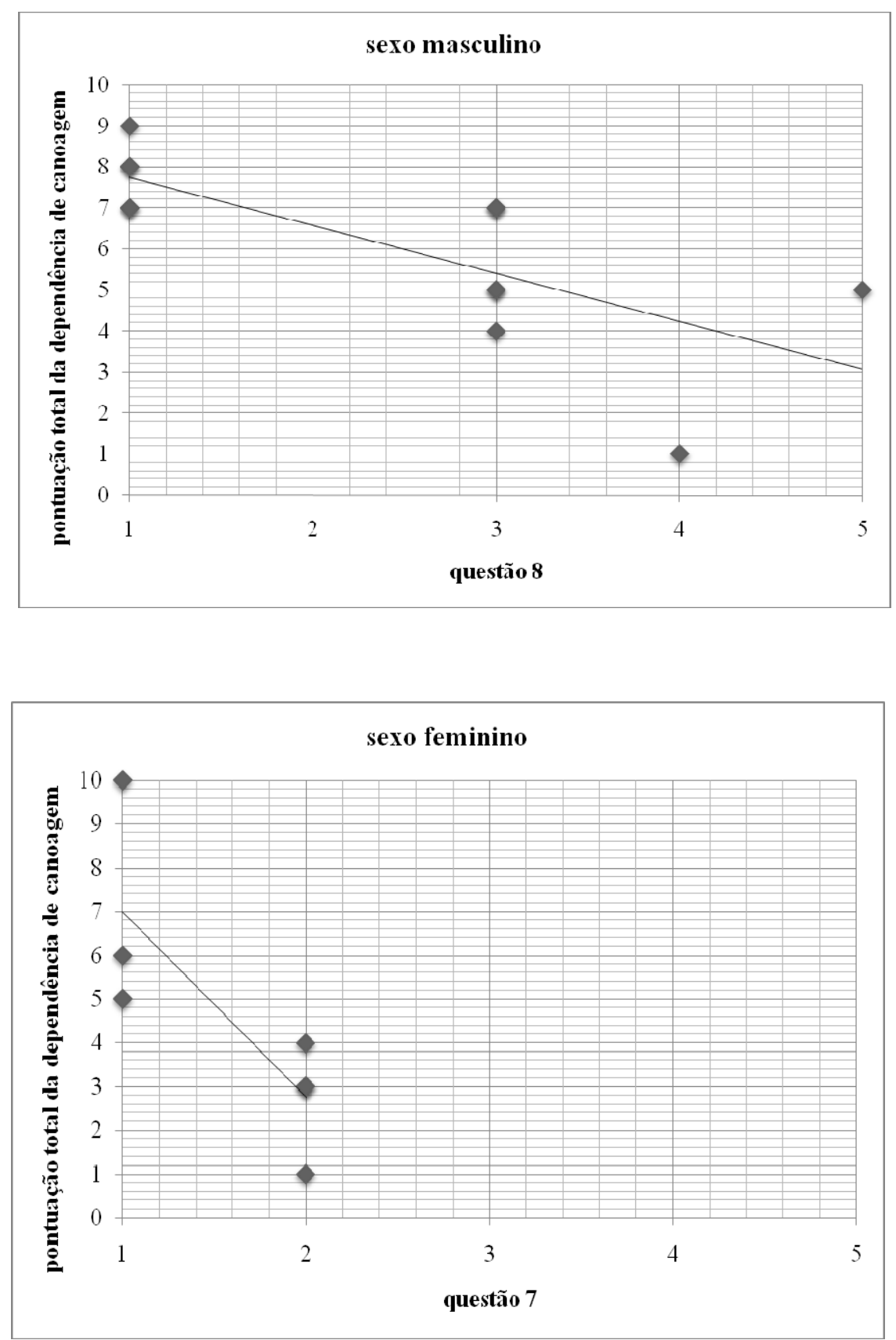

Figura 2. Diagrama de dispersão, para cada sexo, da questão que apresentou associação mais forte (questão 8 para o sexo masculino e questão 7 para o sexo feminino) com a pontuação total.

\section{Discussão}

Os valores encontrados para a dependência psicológica de prática de canoagem foram diferentes aos encontrados na literatura quando outras modalidades foram analisadas. Enquanto estudos realizados com maratonistas que treinam sistematicamente 4 vezes na semana e possuem um tempo de 4 a 8 anos de prática (ROSA, MELLO e SOUZA-FORMIGONI, 2003), o presente estudo mostrou que os atletas da canoagem iniciaram seus treinamentos em um período semelhante, mas alguns deles mostramse com início precoce da prática da modalidade e ainda parecem treinar com uma maior freqüência semanal.

Alguns autores apresentam valores de $5,4 \pm 2,0$ pontos para a pontuação geral da 
Escala de Dependência da prática de corridas em maratonistas do sexo feminino (ROSA, MELLO e SOUZA-FORMIGONI, 2003), estando os atletas de ambos os sexos da canoagem com uma pontuação similar ( $5,47 \pm 2,41$ pontos). Porém ao analisar os resultados da pontuação por sexo dentro da modalidade canoagem, nota-se que os atletas do sexo masculino apresentam pontuação superior $(6,08 \pm 2,19$ pontos) e as atletas do sexo feminino apresentaram pontuação inferior $(4,43 \pm 2,57$ pontos $)$ quando comparados aos maratonistas. No entanto, não foram encontradas diferenças estatisticamente significativas $(p=0,176)$ comparando os atletas do gênero masculino e feminino.

Um fator preocupante relacionado à dependência do esporte foi a resposta atribuída pelos atletas, os quais afirmaram que em qualquer condição, como por exemplo chuva, frio e calor, o treinamento é realizado. Isto pode vir ao encontro das afirmações de autores que mencionam a prática excessiva de exercícios como possível desencadeante de comportamentos compulsivos (ROSA, MELLO e SOUZA-FORMIGONI, 2003; BAMBER et al., 2003). Outros autores também afirmam que aqueles atletas que continuam a prática de exercícios mesmo quando se encontram doentes, lesionados ou com qualquer contra indicação médica, podem vir a apresentar estes comportamentos, o que leva os treinadores a uma maior atenção aos seus atletas (BAMBER et al., 2000; DECOVERLEY, 1987). Por outro lado, segundo Sánchez e Torregrosa (2005) a emoção durante a prática esportiva de alto rendimento é essencial para a busca do melhor desempenho e qualquer intervenção deve ser individualizada e não limitar-se, por exemplo, a redução apenas da ansiedade.

O máximo rendimento do atleta ocorre quando o mesmo se encontra em um nível intermediário de ansiedade (COZZANI et al.,1997). Quando estes se encontram muito baixos ou muito elevados, o desempenho pode ser prejudicado. Esta afirmação é de grande importância, pois envolve alguns componentes do organismo humano, como por exemplo, os fisiológicos e os psicológicos (VAQUERO, 2005). Diante disso, as respostas dos atletas de canoagem podem ser refletidas, uma vez que, a maioria deles sente-se mais cansados quando não realizam os treinamentos. Isto pode influenciar o desempenho e aumentar a dificuldade da tarefa e a sensação de execução da remada. Outro fato a ser considerado é a sensação de culpa mencionada pelos atletas de ambos os sexos. $28,57 \%$ das mulheres relatam que esta sensação ocorre quando os treinos deixam de ser realizados.

Lavoura, Castellani e Machado (2005) avaliaram por meio da aplicação do questionário CSAI-2 (Competitive State Ansiety Invetory - 2), os níveis de ansiedade pré-competitiva em 19 atletas da canoagem slalom. Os resultados indicam que fatores como ansiedade somática como, corpo tenso ou relaxado, foram fatores presentes em quase todos os atletas. Neste estudo, além da tensão, o relaxamento também foi mencionado pelos atletas da seleção brasileira de canoagem velocidade, dados estes que vão ao encontro do estudo de Lavoura, Castelani e Machado (2005). Estas conclusões são importantes, uma vez que, os mesmos autores afirmam que o nível de ansiedade interferiu nos resultados dos atletas estudados, obtendo estes, classificações insatisfatórias nas provas. Para o melhor desempenho os atletas têm que conseguir se motivar, por meio de motivações intrínsecas, geradas por variáveis individuais e assim somálas às motivações extrínsecas e aos incentivos, diante de fatores ambientais e sociais (VAQUERO, 2005).

Assim como demonstram Lavoura, Castelani e Machado (2005), os atletas com maior tempo de experiência no esporte conseguem controlar melhor a ansiedade pré-competição. No caso dos canoístas de velocidade o mesmo ocorreu, pois com o resultado das provas obtidas na competição nacional onde os dados do presente estudo foram coletados, pode-se inferir a relação entre tempo do esporte e controle da ansiedade, pois como já foi mencionado anteriormente, estes atletas iniciaram seus treinos com idades inferiores aos maratonistas, por exemplo (ROSA, MELLO e SOUZA-FORMIGONI, 2003). Outro ponto que pode ser evidenciado está no estudo de Irazusta e Arruza (2006) os quais afirmam que nos atletas com melhores resultados em competições são constatadas maiores satisfações, diversão e motivação.

Para alguns autores, as mulheres apresentam maiores escores de dependência de exercício do que homens, quando pareados em relação ao volume de treinamento (PIERCE, ROHALY e FRITCHLEY, 1997). Porém, no presente estudo, 
observa-se a similaridade entre o volume de treinamento das atletas femininas e dos atletas masculinos, os quais treinam, respectivamente, durante 6 e de 6 a 7 dias na semana.

Segundo Masters e Lambert (1989) mulheres envolvidas em grandes rotinas de exercícios físicos possuem menor aprovação social do que homens. Sendo assim, as atletas que persistem nos treinamentos podem desenvolver maior percepção da dependência devido às pressões sociais, o que leva a um menor envolvimento nas atividades sociais e maior com as atividades esportivas. Estas afirmações vão ao encontro dos resultados encontrados pelo presente estudo que evidenciaram índices de percepção em relação às atividades sociais diminuídas com a prática da modalidade. O mesmo não ocorre com os homens, pois estes afirmam que com a prática da modalidade suas percepções se tornaram aumentadas. No que diz respeito às influências no estilo de vida, $75 \%$ dos homens e $71,42 \%$ das mulheres, afirmam existir esta relação entre canoagem e estilo de vida.

Um dos fatores que englobam o estilo de vida saudável se refere ao processo de trabalho, acrescido de todas as relações que nele se desenvolvem e à vida social, cultural e aos valores do indivíduo (BREILH, 1995). Sendo assim, a qualidade de vida de cada grupo é determinada pela forma como esse se reproduz socialmente (BREILH, 1990). Existe então, uma conotação diferente de qualidade de vida para cada indivíduo, que é decorrente da inserção desses na sociedade, o que conseqüentemente pode trazer influências na vida profissional dos atletas.

Também tem sido sugerido pela literatura que a maior incidência de transtornos alimentares entre mulheres explicaria os altos níveis de dependência de exercício, que podem ser associados a tais transtornos (BAMBER, COCKERILL e CARROLL, 2000; BAMBER et al., 2000; LYONS e CROMEY, 1989). Fato este, que mais uma vez deve ser considerado, pois dependendo da dosagem do treinamento as mulheres podem cair na chamada tríade da mulher atleta (amenorréia, alimentação desordenada e osteoporose) (HALL, 2000).

Este fato é interessante também, pelos atletas possuírem a consciência da necessidade da interrupção da rotina de treinamento em determinadas épocas (Tabela 3). Opiniões estas que devem ser melhores observadas, uma vez que, $16,67 \%$ dos homens discordam muito com esta afirmação, demonstrando que em seus pensamentos a prática da canoagem deve ser constante, mesmo que o treinamento exija um período de compensação (DANTAS, 1998).

A dependência da modalidade também pode estar associada a conversas informais com amigos e familiares, por exemplo. $O$ que demonstra que $66,67 \%$ dos homens e $42,86 \%$ das mulheres utilizam-se da canoagem como assunto principal em seus diálogos, mostrando que o profissionalismo está em todas as etapas da construção da busca dos objetivos. Porém com relação ao interesse pela canoagem e suas relações com problemas nas relações familiares e interpessoais, $41,67 \%$ dos homens e $57,13 \%$ das mulheres não concordam que a canoagem esteja agindo neste sentido. Mesmo que 33,33\% dos homens e $28,57 \%$ das mulheres apresentem pouco prazer durante a execução das sessões de canoagem, pode-se perceber que as atividades extras contidas no programa de periodização que são desenvolvidas pelos atletas durante as etapas do treino são de grande importância para o desempenho.

Além disso, a grande maioria dos atletas afirma que a canoagem é uma das principais formas de recreação. Estes resultados demonstram que além das atividades desenvolvidas como "trabalho" os atletas em seus momentos de lazer continuam desenvolvendo a mesma modalidade. Assim, há necessidade de desenvolvimento de intervenção propondo atividades diversificadas de forma que a vida dos atletas não esteja restrita apenas à canoagem, principalmente nos momentos em que os mesmos não estejam em treinamento.

Com relação às correlações feitas no estudo foram encontradas associações diferenciadas entre os sexos para a pontuação total. Ao analisar os indivíduos do sexo masculino as questões 5 , 8 e 9 se mostraram como sendo as mais relacionadas à dependência do esporte. Essas associações indicam que há tendência em se concordar muito com as afirmações de que quando não se treina há sentimento de culpa pelos atletas (questão 5); treinar ser a principal forma de recreação (questão 8) e a canoagem ser um assunto comum durante as conversas dos atletas (questão 9). Para as atletas do sexo 
feminino as associações foram para as questões 2 e 7, que indicam respectivamente tendências em se sentir culpadas quando não realizam uma sessão de treino e sentimento de prazer nas sessões de treinamento.

\section{Conclusão}

Os escores da dependência da canoagem não se mostraram estatisticamente diferentes entre os sexos. Quando comparados a outras modalidades, como por exemplo, atletas maratonistas, os atletas de canoagem velocidade mostram-se mais dependentes do esporte, o que faz com que a modalidade seja geradora do estilo de vida adotado pelos atletas desse estudo.

Com relação às comparações entre os sexos do presente estudo se pode observar que houve diferenças para as atividades sociais. Estas se mostraram aumentadas para os homens e diminuídas para as mulheres. O treinamento em ambientes desfavoráveis foi observado apenas nas práticas dos atletas do sexo masculino.

Sugere-se ainda estudos mais aprofundados relacionados à dependência psicológica do esporte, uma vez que esta pode interferir sobre os aspectos fisiológicos assim como nos próprios treinamentos e na vida social dos atletas.

\section{Referências}

BAMBER, D.; COCKERILL, I. M.; CARROLL, D. The pathological status of exercise dependence. British Journal of Sports Medicine, London, v. 34 , n. 2, p. 125-32, 2000.

BAMBER, D., COCKERILL, I.M., RODGERS, S.; CARROLL, D. It's exercise or nothing: a qualitative analysis of exercise dependence. British Journal of Sports Medicine, London, v. 34 , n. 6, p. 423-30, 2000.

BAMBER, D.J., COCKERILL, I.M., RODGERS, S.; CARROLL, D. Diagnostic criteria for exercise dependence in women. British Journal of Sports Medicine, London, v. 37, n. 5, p. 393-400, 2003.

BORGES, T. O. Canoagem Velocidade: Dinâmica das cargas de treinamento no macrociclo e a dinâmica da alteração de marcadores funcionais externos. Campinas, 2008. Dissertação (Mestrado em Educação Física) - Universidade Estadual de Campinas, Campinas.

BREILH, J. Nuevos conceptos y técnicas de investigación. 2a ed. Quito: CEAS, 1995.
BREILH, J. Deterioro de la vida: un instrumento para análisis de prioridades regionales en lo social y la salud. Quito: CEAS, 1990.

COZZANI, M.; MACHADO, A. A.; VIEIRA, E. C.; NASCIMENTO, A. L. Ansiedade: interferências no contexto esportivo. In: MACHADO, A. A. (org.) Psicologia do Esporte temas emergentes. Jundiaí: Fontoura, 1997.

DANTAS, E .H. M. A prática da preparação física. $4^{\mathrm{a}}$ Ed. Rio de Janeiro: Shape, 1998

DECOVERLEY, V. D. M. W. Exercise dependence. British Journal of Addiction, London, v. 82, p. 735-40, 1987.

HAILEY, B. J.; BAILEY, L. A. Negative addiction in runners: a quantitative ap-proach. Journal of Sport Behavior, Mobile, v. 5, p. 150-4, 1982.

HALL, S. Biomecânica básica. Rio de Janeiro: Editora Guanabara Koogan S.A, 2000.

IRAZUSTA, S.; ARRUZA, J. Influencia de variables psicológicas en el rendimiento de jugadores amateurs de golf. Revista de Psicología del Deporte, Palma, v. 15, n. 1, p. 127-138, 2006.

LAVOURA, T. N.; CASTELLANI, R. M.; MACHADO, A. A. Canoagem Slalom: Ansiedade X Rendimento. Disponível em: $<$ http://cbca.org.br/biblioteca/arquivos/biblioteca ansiedadexrendi mento 2005 tiago lavoura.pdf> em 20/09/2005.

LEMOS, L. F. C.; PRANKE, G. I.; TEIXEIRA, C. S. Metodologia para o aprendizado da canoagem. Lecturas Educación Física y Deportes, Buenos Aires, v. 12, n. 114, 2007.

LYONS, H. A.; CROMEY, R. Case report. Compulsive jogging: exercise dependence and associated disorder of eating. Ulster Medical Journal, Belfast, v. 58, p. 100-102, 1989.

MALINA, R. M. Tracking of physical activity and physical fitness across the lifespan. Research Quarterly Exercise and Sport, Washington, v. 64, p. 48-57, 1996.

MASTERS, K. S.; LAMBERT, M. J. On gender comparison and construct validity: an examination of the commitment to running scale in a sample of marathon runners. Journal of Sport Behavior, Mobile, v. 12, p. 196-203, 1989.

MORGAN, W. P. Negative addiction in runners. The Physician and Sports Medicine, Berwyn, v. 7, p. 56-63, 1979. 
PIERCE, E. F.; ROHALY, K. A.; FRITCHLEY, B.

Sex differences on exercise dependence for men and women in a marathon road race. Perceptual and Motor Skills, Missoula, v. 84, p. 991-994, 1997.

ROSA, D. A.; MELLO, M. T.; SOUZA-

FORMIGONI M. L. O. Dependência da prática do exercício físico: estudo com maratonistas brasileiros. Revista Brasileira de Medicina do Esporte, São Paulo, v. 9, n. 1, p. 9-14, 2003.

SÁNCHEZ, X.; TORREGROSA, M. El papel de los factores psicológicos en la escalada deportiva: un análisis cualitativo. Revista de Psicología del Deporte, Palma, v. 14, n. 2, p. 177-194, 2005.

VAQUERO, P. D. Motivación, incentivos y rendimiento. Estudio de un Caso en hockey sobre césped. Revista de Psicología del Deporte, Palma, v. 14, n. 2, p. 271-281, 2005.

Endereço:

Luiz Fernando Cuozzo Lemos UFSM - Centro de Educação Física e Desportos Laboratório de Biomecânica

Faixa de Camobi, km 9,

Santa Maria RS Brasil

97105-900

e-mail: luizcanoagem@yahoo.com.br

Recebido em: 29 de maio de 2009.

Aceito em: 18 de fevereiro de 2010.

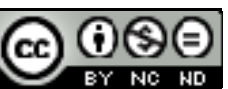

Motriz. Revista de Educação Física. UNESP, Rio Claro, SP, Brasil - eISSN: 1980-6574 - está licenciada sob Licença Creative Commons 